\title{
Políticas de educação bilíngue para surdos: o contexto brasileiro
}

\section{Bilingual education policies for the deaf: the Brazilian context}

\author{
Sueli Fernandes ${ }^{1}$ \\ Laura Ceretta Moreira ${ }^{1}$
}

\begin{abstract}
RESUMO
Este artigo propõe-se a apresentar um panorama das políticas educacionais para surdos, desde a década de 1990, demarcando as inúmeras disputas ideológicas que influenciaram diretamente os campos da política linguística e das políticas de educação inclusiva para esse grupo de estudantes. Assumimos como elemento determinante de análise a gestão pública das línguas adotadas na educação de surdos para avaliar a efetividade das políticas de educação inclusiva, considerando que a complexa situação de bilinguismo dos surdos está diluída ao, não menos complexo, processo de inclusão de pessoas com deficiência na escola comum. Assim, demonstramos que há um desvio de foco (derivado de um desvio na concepção de sujeito surdo) no conjunto de textos oficiais que constituem as diretrizes filosóficas e legais para a educação desses estudantes, cujo impacto central é não assegurar o direito à língua de sinais brasileira (Libras) como língua materna na infância, conforme reivindicam os movimentos surdos e está assegurado na letra da lei. Aponta-se a política linguística como uma variável determinante no debate da conjuntura nacional da educação de surdos brasileiros, ainda que nem sempre a ela seja dada centralidade pelo poder público, na atualidade. Ao analisar a política linguística refletida no percurso histórico da educação de surdos, realizamos uma análise crítica sobre os avanços e dificuldades no processo de escolarização (dito) bilíngue de surdos no contexto da educação (dita) inclusiva.
\end{abstract}

Palavras-chave: políticas de educação inclusiva; política linguística; educação bilíngue para surdos.

DOI: $10.1590 / 0104-4060.37014$

1 Universidade Federal do Paraná. Curitiba, Paraná, Brasil. Setor de Educação. R. General Carneiro, $\mathrm{n}^{\circ}$ 460. CEP: 80060-150. 


\begin{abstract}
This article has been developed to illustrate the scope of the Brazilian educational policies for the deaf since the 1990's, highlighting the ideological disputes that have had a direct impact on the fields of linguistic and inclusive education policies concerning the group mentioned above. The public management of the languages adopted for the education of the deaf was used as our key element of analysis to assess the effectiveness of those policies. The complex situation of bilingual education for that group is also taken into consideration. It is diluted in the process of including disabled people in regular schools, which is not less complex. Therefore, we show that there is a diversion (rooting from a misconception of the deaf subject) in the official texts that constitute the legal and philosophical guidelines for the education of these students. As a result of that, the access to the Brazilian Sign Language (Libras) as a first language to that population, a mother tongue since childhood, as requested by the deaf community and ensured by law, is not safeguarded. We point out the importance of a linguistic policy as a crucial element on the current situation of the national policy for the education of the deaf debate, whether or not it resonates with the present government point of view. By analyzing historically the linguistic policy for deaf education, we are also able to make a critical review of the advances and difficulties of the so-called bilingual education for the deaf in our so-called inclusive education context.
\end{abstract}

Keywords: policies on inclusive education; linguistic policy; bilingual education for the deaf.

\title{
Movimentos surdos e a insurgência do campo dos estudos surdos em educação
}

Podemos indicar os anos 1990 como o marco da insurgência dos movimentos surdos brasileiros. Nessa década, iniciam-se os debates conceituais sobre língua de sinais, bilinguismo, os reflexos dos modelos clínicos-terapêuticos e socioantropológicos na educação de surdos, teorizações sobre a cultura e identidades surdas e os impactos de todos esses estudos na organização de um processo de educação bilíngue para surdos no Brasil.

Esse movimento foi protagonizado, por um lado, por ativistas surdos, seus familiares e profissionais da área e, por outro lado, por pesquisadores que buscavam edificar academicamente um campo epistemológico, localizando os movimentos surdos no espaço das lutas multiculturalistas mundiais, empreen- 
didas por grupos políticos minoritários em defesa de direitos étnico-raciais, de gênero, de orientação sexual, de liberdade religiosa, entre outros casos.

Mas pelo que lutavam os surdos brasileiros? Contra que se opunham e o que denunciavam/reivindicavam?

Voltemos um pouco mais na história para entender o significado social dessa mudança que se deu no final do século XX.

Era 1880. Na Europa e na América, vivia-se o auge da controvérsia envolvendo metodologias de ensino que contrapunham fala e língua de sinais como meios de instrução e comunicação nas escolas de surdos. Em Milão, na Itália, durante o Segundo Congresso Internacional de Educação de Surdos, a decisão de proibir a língua de sinais e seu legado cultural no processo educacional de surdos teria impactos definitivos para a vida das pessoas surdas nos próximos cem anos.

Dos 164 delegados presentes, representando a Itália (87 delegados), a França (53 delegados), a Inglaterra, a América, a Suécia, a Bélgica e a Alemanha, apenas dois eram surdos: James Denison, da delegação de Washington DC, USA e Claudius Forestier, diretor da escola de surdos de Lyon, na França. Foram oito as resoluções votadas, das quais as duas principais encaminhavam os objetivos do Congresso: impor e votar o Método Oral Puro como principal meio de instrução, em detrimento da língua de sinais na educação de surdos, e monopolizar a educação de surdos, banindo os professores surdos das escolas.

O Congresso de Milão é o símbolo de um período em que a educação de surdos passou a ser planejada e praticada por ouvintes, à revelia do que os próprios educadores surdos defendiam como princípio pedagógico básico: aprender com base na língua de sinais.

Um século depois, Carlos Skliar (1998), importante e influente teórico do bilinguismo e da diferença surda, analisa um dos fatores históricos que contextualizou e legitimou a proibição da língua de sinais, à época: os esforços em estabelecer um estado italiano, recentemente emancipado, coeso e unificado, política e linguisticamente. A Itália, depois da Unificação pós-década de 1860, além dos problemas graves de ordem política, econômica e social que vivia, deparava-se com a diversidade linguística da grande massa da população que se comunicava em dialetos e continuava condenada ao analfabetismo, em oposição a uma minoria letrada que falava e escrevia a língua italiana. Poetas e escritores (milaneses, em especial) contribuem para a criação de um contexto literário que estimulasse a unificação ao registrar em suas obras um padrão linguístico do dialeto florentino falado pelo povo, com a intenção de eliminar as diferenças que se tornavam cada vez maiores entre a língua escrita e a língua falada, entre a cultura burguesa e o distanciamento do povo (MARTINS, 2011). Nesse contexto, a eliminação da língua de sinais das escolas contribuía para atenuar um fator 
de desvio linguístico, obrigando também as crianças surdas a aprender a falar a língua comum, a despeito de sua incapacidade orgânica de fazê-lo.

Este é um notório exemplo dos impactos que uma política linguística tem no campo educacional.

Caberia aqui uma ampla digressão histórica sob os impactos e desdobramentos das decisões político-pedagógicas formalmente definidas no Congresso de Milão e legitimadas pelos atos cruéis que passaram a ser praticados envolvendo crianças, jovens e adultos surdos que, até então, sinalizavam em liberdade absoluta. Porém, para ilustrar o efeito deletério das decisões tomadas sobre a vida dos surdos, tomemos o depoimento de Harlan Lane, professor e ativista do movimento surdo em seu livro When the Mind Hears: a history of the deaf, na década de 1980:

Agora, cem anos depois, as águas parecem refluir ligeiramente em alguns estados norte-americanos, na Dinamarca e na Suécia, na França, o que permite um vislumbre de algumas agitações preliminares de vida: aqui, vemos as mãos de um intérprete em movimento; lá, uma atriz surda sinaliza; em outro lugar, um professor sinaliza em sua sala de aula. Ainda assim, em lugar nenhum, há comunidades sinalizando a exemplo do estatuto de outras minorias linguísticas, em nenhum lugar é oportunizado aos surdos exercer influência significativa na educação das crianças surdas, em nenhum lugar surdos são capazes de concluir a educação básica em números substanciais, em nenhum lugar a política nacional implementa o que os ideais nacionais exigem: a autorrealização para os surdos como para todos os outros cidadãos (LANE, 1984, p. 377).

Uma língua oprimida, uma cultura dizimada, um atraso social que perpetuou o estereótipo de deficiência e incapacidade dos cidadãos surdos, cuja diferença, até o século XIX, se manifestava prioritariamente em termos linguísticos.

Diante desse cenário que amordaçou a língua de sinais por um século, a comunidade surda vê-se representada na essência da estratégia política do movimento multiculturalista nos anos 1990, qual seja, o reconhecimento da identidade cultural como processo permanente da "representação e construção do eu como sujeito único e igual a si mesmo e o uso desta como referência de liberdade, felicidade e cidadania, tanto nas relações interpessoais como intergrupais e internacionais" (SAWAIA, 2001) recriadas a partir de características como raça, religião, etnia, para se refugiar da globalização homogeneizadora (IANNI, 1996, p. 25). 
A partir dessa compreensão, o campo epistemológico denominado Estudos Surdos (Deaf Studies) edifica sua teorização tomando a contribuição da crítica pós-moderna em educação. Sua estratégia repousa em dar centralidade ao papel da linguagem na produção de experiências, estabelecendo uma epistemologia que permita a compreensão e a problematização da questão das diferenças e da diversidade. Em outras palavras, "a diferença é politizada ao ser situada em conflitos sociais e históricos reais em vez de ser, simplesmente, contradições textuais ou semióticas" (EBERT apud MCLAREN, 1997, p. 68).

A criação do espaço discursivo dos Estudos Surdos constituiu, nessa lógica, uma possibilidade de problematizar os discursos hegemônicos sobre a surdez, buscando uma transformação nas representações dominantes em relação às identidades surdas, que as colocavam no território da anormalidade ou da deficiência. Enlaçado à trama epistemológica das diferenças teorizadas no campo dos Estudos Culturais na pós-modernidade (HALL, 1997), o movimento surdo brasileiro capilariza suas ações em, basicamente, duas vertentes:

a) Uma delas, engendrada por mobilização de surdos, pais e profissionais que se originam no sul do país e espocam por outros estados, reivindicava a inversão da narrativa social dominante que essencializava os surdos como indivíduos "deficientes auditivos" para o reconhecimento de sua condição coletiva de "minoria linguística", defendendo o direito ao acesso e uso da língua de sinais brasileira como língua materna, na família, na escola e no trabalho;

b) A outra vertente inaugurava um campo discursivo acadêmico que representasse pela linguagem as mudanças nas concepções e práticas em ação. A criação e localização dos Estudos Surdos no contexto dos Estudos Multiculturais propõe a ruptura da discussão da surdez no contexto historicamente obrigatório da Educação Especial, das deficiências e das patologias de linguagem (SKLIAR, 1998).

"Um campo é um campo de forças, e um campo de lutas para transformar as relações de forças" (BOURDIEU, 2011). A iniciativa acadêmica pioneira de formação desse campo discursivo se deu na Universidade Federal do Rio Grande do Sul (UFRGS), em seu Programa de Pós-Graduação em Educação, na década de 1990, onde se constituiu o primeiro Núcleo de Pesquisa em Políticas de Educação para Surdos (NUPPES), sob a influência e mediação central do professor visitante argentino Carlos Skliar. O NUPPES forma importantes pesquisadores pioneiros na área da Educação de Surdos como: Adriana Thoma, Lodenir Becker Karnopp, Liliane Ferrari Giardini, Madalena Klein, Maura Corcini Lopes, para citar alguns nomes. $\mathrm{O}$ fato demarcador de uma nova política institucional para 
surdos foi o ingresso da primeira pós-graduanda surda - Gladis Perlin - que veio a se tornar a primeira doutora surda em educação no Brasil. Lopes (2007, p. 13) avalia que a disseminação da língua brasileira de sinais, inicialmente, seguida da ampla gama de temas, problemas e enfoques teóricos desenvolvidos pelo NUPPES e outros pesquisadores brasileiros que se mobilizavam em seus contextos a partir de abordagens antropológicas, linguísticas e culturais dos surdos constituíram a base para um grande movimento de ruptura com uma concepção de Educação Especial fortemente marcada pelo viés clínico e, decorrente dela, por um projeto educacional que essencializava a diferença surda em termos audiológicos.

O V Congresso Latino-Americano de Educação Bilíngue para Surdos, realizado pelo NUPPES/UFRGS, em 1999, reuniu pesquisadores, profissionais, familiares e lideranças da comunidade surda mundial (Brasil, América Latina, América do Norte e Europa) e visibilizou a força da mobilização política da comunidade surda. Previamente ao Congresso, ocorreu um espaço auto-organizado de discussão de temáticas de interesse da comunidade surda com relação às identidades, à cultura e à educação de surdos, que resultou em um documento intitulado "A Educação que nós, surdos, queremos" (FENEIS, 1999), referência para a elaboração de um decreto que iria regulamentar a Lei de Libras no Brasil, posteriormente. Foram ideias fundadoras da futura política nacional de educação de surdos:

25. Elaborar uma política de educação de surdos com escolas específicas para surdos (p. 5).

26. Considerar que a escola de surdos é necessária e deve oferecer educação voltada para princípios culturais e humanísticos, promovendo o desenvolvimento de indivíduos cidadãos e sendo um centro de encontro com o semelhante para produção inicial da identidade surda (p. 5).

53. Substituir o termo de "deficiente auditivo" por surdo considerando que o deficiente auditivo e o surdo não têm a mesma identidade: o deficiente auditivo usa comunicação auditiva, tendo restos auditivos que podem ser corrigidos com aparelhos; o surdo usa comunicação visual (línguas de sinais) e não usa comunicação auditiva (p. 8).

58. Propor o reconhecimento e a regulamentação da língua de sinais a nível federal, estadual e municipal para ser usada em escolas, universidades, entidades e órgãos públicos e privados (p. 9).

59. Considerar que as línguas de sinais são línguas naturais das comunidades surdas, constituindo línguas completas e com estrutura independente das línguas orais (p. 9). 
71. Fazer da língua de sinais uma disciplina no currículo, envolvendo o ensino de sua morfologia, sintaxe, e semântica (p. 10).

(FENEIS, 1999) $)^{2}$

Essas reivindicações dão destaque à nova concepção de surdez, sujeito surdo e educação de surdos que se pretende afirmar, a partir do campo epistemológico dos Estudos Surdos com destaque ao papel central da língua, da cultura e da identidade surdas como campo discursivo de luta, como prática de significação, de produção de sentido sobre o mundo.

Dentre as questões substantivas que sedimentaram o espaço discursivo dos Estudos Surdos, distanciado da ditadura da normalidade, está localizada a discussão em torno do direito a uma educação bilíngue, como espaço de resistência e edificação da identidade surda.

Em termos genéricos, o bilinguismo social envolvendo minorias linguísticas contempla contextos em que coexistem duas (ou mais) formas linguísticas com divisão funcional de uso: uma variedade alta respeitada (no caso, o português) que é oficial, fortemente padronizada, adotada na educação formal, em oposição a uma variedade baixa que não goza de prestígio social e é utilizada em situações cotidianas informais (CALVET, 2002). Note-se que essa definição baliza uma compreensão de que não é a língua que é minoritária, ou invisibilizada socialmente, mas a comunidade que a fala.

Desse modo, o bilinguismo dos surdos brasileiros constitui uma situação em que a comunidade surda tem um alto grau de identificação com a língua brasileira de sinais (Libras) e a utiliza cotidianamente no encontro surdo-surdo, ou surdo-ouvinte bilíngue. Por sua manifestação se dar por signos visuais (e não orais-auditivos, como na grande maioria das línguas naturais), implica uma constituição de sentidos sobre o mundo diferenciada, forjando uma cultura visual (com produções na arte, na literatura, no humor, na vida social e esportiva...) ${ }^{3}$ com impactos que assemelham os surdos a outros grupos étnicos que utilizam línguas minoritárias (como os indígenas, por exemplo). A despeito dessa identificação com sua língua de conforto, a língua portuguesa é a língua oficial do país, pela qual se realizam as interações sociais básicas, desde a família, à escola e o trabalho. Isso impõe a necessidade do uso social do português em ambientes formais, que assume o status de segunda língua para os surdos brasileiros,

2 Documento elaborado pela comunidade surda a partir do Pré-Congresso ao V Congresso Latino-americano de educação bilingue para surdos, realizado em Porto Alegre/RS, nos dias 20 a 24 de abril de 1999.

3 Ver neste trabalho os artigos de Karnopp e Hessel, "Humor na literatura surda", e de Sutton-Spence, "Por que precisamos de poesia sinalizada em educação bilíngue?" 
obrigatório no processo de escolarização dos surdos. Essa situação caracteriza formalmente a condição bilíngue dos surdos brasileiros.

Em recente documento elaborado por um grupo de trabalho instituído pelo MEC/SEESP, formado por profissionais e pesquisadores da área ${ }^{4}$, que define subsídios para a Política Linguística de Educação Bilíngue: Língua Brasileira de Sinais e Língua Portuguesa, apresenta-se a seguinte definição:

A Educação Bilíngue de surdos envolve a criação de ambientes linguísticos para a aquisição da Libras como primeira língua (L1) por crianças surdas, no tempo de desenvolvimento linguístico esperado e similar ao das crianças ouvintes, e a aquisição do português como segunda língua (L2). [...] O objetivo é garantir a aquisição e a aprendizagem das línguas envolvidas como condição necessária à educação do surdo, construindo sua identidade linguística e cultural em Libras e concluir a educação básica em situação de igualdade com as crianças ouvintes e falantes do português (BRASIL, 2014, p. 6).

Isso significa que a Libras deveria ser aprendida preferencialmente de zero a três anos, garantida como primeira língua (L1) e como língua de instrução, além do aprendizado do português como língua oficial do país para garantir o letramento e acesso ao conhecimento formal aos cidadãos surdos brasileiros.

No entanto, o fato real é que as famílias dos surdos constituem contextos monolíngues em língua portuguesa pelo fato de que as crianças surdas, em mais de $95 \%$ dos casos, são nascidas e criadas em meios ouvintes. Na infância, não se apropriam de referências culturais da comunidade surda e não têm interlocutores fluentes em Libras para garantir seu direito à língua materna, até os três anos. Este relato, extraído do livro da eminente atriz e escritora surda Emanuelle Laboritt sobre a experiência do "Ser Surdo" em uma família/sociedade ouvinte, traz a imagem vivida das reflexões que desenvolvemos:

Os adultos ouvintes que privam seus filhos da língua de sinais nunca compreenderão o que se passa na cabeça de uma criança surda. Há a solidão, e a resistência, a sede de se comunicar e algumas vezes, o ódio. A exclusão da família, da casa onde todos falam sem se preocupar com você. Porque é preciso sempre pedir, puxar alguém pela manga ou pelo

4 Grupo de Trabalho designado por Portaria Ministerial para elencar subsídios à Política Linguística de Educação Bilíngue - Língua Brasileira de Sinais e Língua Portuguesa. 
vestido para saber, um pouco, um pouquinho, daquilo que se passa em sua volta. Caso contrário, a vida é um filme mudo, sem legendas. (LABORITT, 1994 p. 59).

Essas barreiras linguísticas e comunicativas decorrentes da ausência de uma língua comum, compartilhada entre pais e filhos na família, fica aprofundada quando se inicia a escolarização formal, pela ainda incipiente situação das comunidades bilíngues nas escolas: professores, a quem, em última análise se deposita a responsabilidade histórica pela inclusão de seus alunos, não falam Libras; os intérpretes que têm atuado como mediadores de comunicação e apoio pedagógico nas escolas têm uma formação ainda deficitária e, decorrente da complexidade do processo de se tornarem proficientes em uma língua ainda marginalizada socialmente, utilizam a Língua de Sinais precariamente de forma bimodal. O bimodalismo constitui uma prática amplamente utilizada por ouvintes não proficientes que falam e sinalizam simultaneamente, na comunicação com os surdos. Geralmente, a língua de sinais é prejudicada, pois a sinalização fica subordinada à gramática da língua portuguesa. Por decorrência, não está garantido aos estudantes surdos nem o acesso aos conteúdos escolares em Libras e nem o domínio daquela que deveria ser a segunda língua no currículo escolar - o português.

Em trabalho anterior ${ }^{5}$ advertimos para o modelo assimilacionista que caracteriza a educação bilíngue dos surdos brasileiros, tendo em vista que o sistema educacional conduz a um monolinguismo, ou a um limitado bilinguismo, em que a língua de sinais tem sido sistematicamente negada como principal meio de comunicação e acesso ao conhecimento, em direção a práticas linguístico-culturais que têm no português sua referência mais significativa. Fruto desse "bilinguismo incipiente", a educação linguística das crianças surdas não constrói referências de identificação culturais positivas e o precário aprendizado da língua portuguesa como segunda língua tem sido o alvo da marginalização e exclusão dos estudantes.

Esse cenário social que liberta a língua, mas não cria espaços efetivos para seu uso e desenvolvimento, conduz para que a configuração identitária mobilize as lutas surdas, a partir da década de 1990, e as referências relativas à identificação linguística.

Sawaia (2001, p. 124) faz uma interessante análise ao tomar o conceito de identidade como referência nas lutas sociais: 
O clamor pela identidade, quer para negá-la, reforçá-la ou construí-la, é parte do confronto de poder na dialética da inclusão/exclusão e sua construção ocorre pela negação dos direitos e pela afirmação de privilégios. Ela exclui e inclui parcelas da população dos direitos de cidadania, sem prejuízo à ordem e harmonia social. (SAWAIA, 2001, p. 122).

Ou seja, a língua de sinais opera, paradoxalmente, como fator de inclusão e de exclusão dos surdos. Ao configurar-se como elemento agregador baseado na experiência cultural comum, a língua de sinais inclui o coletivo surdo no território discursivo da normalidade, da diferença, em detrimento do estigma do déficit auditivo que constituía a narrativa mestra do poderoso discurso clínico-audiológico sobre o indivíduo surdo deficiente. Por outro lado, assumir a diferença linguística como principal traço de identificação expõe a comunidade surda a uma situação de exclusão pelo pouco prestígio social e, embora oficializada, com baixa incidência de usos e funções sociais em espaços formais.

\section{Em defesa da política linguística como fator de inclusão escolar dos surdos}

Como apontado inicialmente, refletir sobre os pontos de contato que determinam demandas da política linguística e ações da política de educação escolar inclusiva não pode ser um elemento que escape ao debate da gestão pública na educação de surdos.

A educação bilíngue para surdos constitui um território de disputas em que Libras e língua portuguesa estão em tensão constante nas interações verbais, posto que são línguas marcadas por relações de poder explicitamente assimétricas no espaço escolar.

A despeito dos avanços políticos (sobretudo legislativos) que reconhecem a situação de bilinguismo dos surdos brasileiros, prevalece a manutenção de uma concepção social na qual esses estudantes são, não apenas, narrados como deficientes da linguagem, mas relegados, de fato, a essa situação, ao não estarem dadas as condições materiais de sua produção histórica como cidadãos bilíngues, desde o seio familiar até círculos sociais mais amplos como é o caso da escola e do trabalho (FERNANDES, no prelo).

O principal nexo de princípio se realiza a partir do pressuposto que uma política de inclusão responsável apenas se efetiva se estiver garantido o tratamento 
diferenciado àqueles que têm como língua materna uma língua diferente daquela falada pela sociedade majoritária. A responsabilidade do Estado consolida-se tanto em seu ordenamento jurídico como na prática de ações afirmativas para defesa da existência, valorização e difusão das línguas minoritárias, por meio da liberdade de uso pelos seus falantes (FERNANDES, 2011).

É histórica a invisibilidade das pessoas surdas e de sua língua de sinais no contexto das políticas de educação de surdos, considerando que a oficialização da Língua Brasileira de Sinais aconteceu há apenas uma década, pela Lei Federal 10.436, em 2002.

No Decreto Federal 5.626/2005 que regulamenta a Lei de Libras, a pessoa surda é definida "como aquela que, por ter perda auditiva, compreende e interage com o mundo por meio de experiências visuais, manifestando sua cultura principalmente pelo uso da Língua Brasileira de Sinais - Libras" [grifos nossos]. Essa configuração identitária é reivindicada pela comunidade surda, em detrimento de uma representação clínica baseada em graus de perda auditiva. No entanto, dizer que pessoa surda é aquela que se comunica por meio da Libras é uma verdade a ser edificada como meta de uma política linguística e educacional, em que as crianças surdas cresceriam em comunidades linguísticas onde a língua de sinais circulasse plenamente, viva, dinâmica e em transformação, por usuários fluentes (surdos e ouvintes).

Ao contrário, os testemunhos de gerações e gerações de surdos, que hoje estão protagonizando os movimentos em defesa da cultura surda e da escola bilíngue $^{6}$, denunciam a educação opressora que tiveram, seja em escolas especiais, seja em escolas "inclusivas", a impossibilidade do encontro criança surda-adulto surdo, a proibição da língua de sinais, a imposição da oralização e da leitura labial, entre outras práticas ouvintistas que lhes cercearam o direito de produzir e se apropriar da sua língua, da cultura visual, da sua história, como expressa esse fragmento extraído da tese de doutorado da professora e pesquisadora surda Karin Strobel:

[...] o que mais marcou na minha vida na escola foi quando a professora disse para mim que fazer os sinais é muito feio, que eu era igualzinho a um macaco, disse que eu sou parecida com o macaco e me obrigava a não fazer os sinais, [...] a professora falava para a minha mãe que eu não devia fazer sinais, minha mãe obedecia e me obrigava a falar, eu sofria porque queria muito de fazer os sinais com os amigos surdos. [...]

6 Ver, neste dossiê, o artigo de Rezende e Campello "Em defesa da escola bilíngue para surdos: a história de lutas do movimento surdo brasileiro". 
Uma vez a professora bateu nas minhas mãos, mandava eu falar certo e brigava comigo por falar errado, ela reclamava comigo dizendo que eu não sabia falar direito, dizia que é muito feio os sinais que eu fazia, eu ficava muito decepcionada porque eu não sabia o que falar e eu sofri muito com isto [Luiza, 33 anos] (STROBEL, 2008, p. 49).

No atual conjunto de textos oficiais que compõem a política de educação bilíngue ${ }^{7}$ para surdos há uma clara ambiguidade na hierarquia de princípios e objetivos que definiriam o foco da educação inclusiva para surdos. Em que pese o reconhecimento da necessidade da educação bilíngue, explicita-se que "o foco do trabalho deve ser a transformação das suas práticas pedagógicas excludentes em inclusivas" em que "a aceitação de sua diferença assegurará a sua aprendizagem" (ALVEZ; FERREIRA; DAMÁZIO, 2010, p. 22). Isto é, ressalta-se a mudança atitudinal como prioritária no processo.

Outro problema que se observa é a ambígua representação dos surdos que circula no conjunto desses documentos oscilando em um pêndulo discursivo que ora balança para uma categorização que toma os surdos como integrantes de um grupo cultural por falarem uma língua própria (a Libras), e ora os classifica como estudantes com deficiência, cujo tratamento diferenciado exigiria recursos de acessibilidade e atendimento educacional especializado (AEE) para ter garantida uma aprendizagem significativa, na qual a Libras figuraria como um recurso educacional.

[...] torna-se urgente repensar a educação escolar dos alunos com surdez, tirando o foco do confronto do uso desta ou daquela língua e buscar redimensionar a discussão acerca do fracasso escolar, situando-a no debate atual acerca da qualidade da educação escolar e das práticas pedagógicas. É preciso construir um campo de comunicação e de interação amplos, possibilitando que a língua de sinais e a língua portuguesa, preferencialmente a escrita, tenham lugares de destaque na escolarização dos alunos com surdez, mas que não sejam o centro de todo o processo educacional (ALVEZ; FERREIRA; DAMÁZIO, 2010, p. 8, grifos nossos).

Na perspectiva inclusiva da educação de "pessoas com surdez", naturaliza-se a desigualdade histórico-social que caracteriza as duas línguas que mobilizam a subjetividade dos surdos brasileiros propondo que a educação que desafia o

7 Brasil (2008); Alvez, Ferreira e Damázio (2010). 
pensamento e as habilidades "para atuar e interagir em um mundo social que é de todos" é aquela que dá "liberdade de o aluno se expressar em uma ou em outra língua". (ALVEZ; FERREIRA; DAMÁZIO, 2010, p. 22). Parece-nos inconcebível colocar em um mesmo patamar línguas com valores sociais e patrimônio histórico e cultural tão desiguais.

Ora, como ignorar que o objeto central na planificação de programas de educação bilíngue é o direito à língua materna? Como desconsiderar a definição que articula educação bilíngue à língua materna, desde 1954, entre as deliberações da UNESCO? Como negar que "bilinguismo é o direito que têm as crianças que utilizam uma língua oficial de serem educadas na sua língua materna"? (SKLIAR, 1998, p. 25).

$\mathrm{Na}$ mesma linha, o antropólogo e consultor do MEC para a política de Educação Escolar Indígena, Luís Grupioni, afirma que o maior saldo da Constituição de 1988 para os grupos indígenas foi o fato de que "eles passaram a ter assegurado o direito à diferença cultural, isto é, o direito a serem índios e permanecerem como tal", em detrimento da perspectiva integracionista que sempre procurou incorporá-los à comunidade nacional (GRUPIONI, 2001, p. 130). Isso significa, prioritariamente, o direito ao uso de suas línguas maternas e processos próprios de aprendizagem, cabendo à escola indígena ser um instrumento de valorização da língua e dos saberes vernáculos. Ou seja, a prática do bilinguismo e da interculturalidade é o que confere tratamento diferenciado à escola indígena em relação às demais escolas do sistema de ensino.

Por que, então, no caso dos surdos, secundariza-se a questão prioritária do direito à Libras como língua materna nas políticas educacionais? Por que, em todos os documentos que compõem o aparato jurídico no que tange à situação dos surdos não há uma diretriz clara e objetiva que aponte estratégias que assegurem às crianças surdas o direito de aprender Libras na infância, até os cinco anos, em escolas públicas bilíngues? Sim, é verdade que em todos esses textos o português figura como segunda língua. Mas o direito a aprender o português como L2 assegura que a primeira língua será a Libras?

Muitos poderiam ser os questionamentos que nos levariam à constatação de que é ainda incipiente o debate da política linguística para surdos no contexto da educação inclusiva.

A transformação da escola adjetivada inclusiva para surdos requereria que a sua língua nativa fosse a língua de instrução, que seu repertório histórico e cultural estivesse contemplado no currículo, que a presença de professores surdos como modelos de identificação linguística e cultural fosse garantida, além de uma adequada pedagogia para o ensino e avaliação do português como segunda língua. Exatamente os mesmos elementos que configuraram as conquistas da educação indígena bilíngue no Brasil. 
Há um evidente desvio de foco na política de educação de surdos quando é secundarizada a questão central, ou seja, o fortalecimento e reconhecimento político da Libras como língua de cultura, com a difusão do principal instrumento para a concretização das comunidades linguísticas: as escolas bilíngues para surdos como espaço fundamental na arquitetura da política de educação inclusiva (FERNANDES, 2011).

Em detrimento desse princípio, o Estado atribui à língua de sinais o status de recurso de acessibilidade para surdos, com o mesmo valor instrumental de outras tecnologias assistivas para pessoas com deficiência, conforme exposto na legislação que regulamenta o Atendimento Educacional Especializado - AEE:

$\S 1^{\circ}$ Considera-se atendimento educacional especializado o conjunto de atividades, recursos de acessibilidade e pedagógicos organizados institucionalmente, prestado de forma complementar ou suplementar à formação dos alunos no ensino regular.

$\S 2^{\circ} \mathrm{A}$ produção e distribuição de recursos educacionais para a acessibilidade incluem livros didáticos e paradidáticos em braile, áudio e Língua Brasileira de Sinais - LIBRAS, laptops com sintetizador de voz, softwares para comunicação alternativa e outras ajudas técnicas que possibilitam o acesso ao currículo (BRASIL, 2008, grifos nossos).

A indiferenciação valorativa entre uma língua que representa a produção histórico-cultural de uma comunidade minoritária e o conjunto de recursos físicos, técnicos e materiais que constituem as tecnologias assistivas ${ }^{8}$ revela um enorme distanciamento dos princípios do bilinguismo. Da mesma forma, quando se impõe que a escolarização de surdos se realize em escolas regulares monolíngues, que não apresentam condições sociolinguísticas para a formação de comunidades de uso da Libras, se efetiva o cerceamento de que as crianças se tornem membros potenciais de uma comunidade linguística viva e autônoma.

Diante dessas considerações, entendemos que uma política inclusiva consistente não pode abrir mão de uma configuração que articula os objetivos da educação escolar e os princípios de formação de comunidades linguísticas

8 São consideradas Tecnologias Assistivas toda e qualquer ferramenta, recurso ou processo utilizado com a finalidade de proporcionar uma maior independência e autonomia à pessoa com deficiência, desde artefatos simples, como uma colher adaptada ou um lápis com uma empunhadura mais grossa para facilitar a preensão, até sofisticados programas especiais de computador que visam à acessibilidade (INCLUSÃO, 2005, p. 26). Disponível em: <http://portal.mec.gov.br/seesp/ arquivos/pdf/revistainclusao2. pdf $>$. 
em Libras. Dito de outra forma, o foco a ser perseguido pelo Estado deveria promover o entrelaçamento entre a política linguística e a política de educação inclusiva para surdos, sobretudo na rede municipal, responsável pela educação infantil e os anos iniciais do ensino fundamental.

\section{Considerações finais}

Avaliar a viabilidade das estratégias adotadas nos textos que sistematizam a política nacional de educação especial e inclusiva (referimo-nos não apenas à legislação, mas também às publicações que orientam a ação pedagógica $)^{9}, 0$ que vem contribuindo para a solução dos desafios concernentes à situação de bilinguismo dos surdos, estabelecendo os possíveis nexos que entrelaçaram os campos das políticas linguísticas e das políticas de educação inclusiva, foi o objetivo deste artigo.

Os fatores que condicionaram a existência de uma política pública específica para surdos ao longo dos últimos anos assumem nuances de sentido social diferenciados desde o momento de sua proposição, pós-década de 1990, e no contexto atual. No início da década de 1990, os movimentos surdos rebelavam-se pela afirmação de sua identidade surda, buscando consolidar a narrativa da alteridade surda a partir de critérios antropológicos fundamentados na identidade cultural e linguística, em oposição à representação audiológica dominante que operava pela manutenção de uma identidade forjada na materialidade da condição biológica da deficiência auditiva como determinante da existência social do sujeito surdo.

A conquista do direito à língua de sinais como produto de identificação cultural e interlocução social determina mudanças no campo político que levou à transformação de arranjos institucionais em vários níveis de ação estatal, a partir de 2000: a inclusão obrigatória da disciplina da Libras nos cursos de formação de professores, a criação de cursos de Licenciatura em Letras Libras e Bacharelado em tradução e interpretação, aberturas de vagas e concursos públicos na área da Língua Brasileira de Sinais, para citar as áreas prioritárias.

Em consequência da incorporação da educação bilíngue ao escopo institucional entram em cena novos atores políticos (associações de surdos, Federação de Surdos, professores bilíngues, tradutores e intérpretes de Libras

9 Ver: $<$ http://portal.mec.gov.br/index.php?option=com_content\&view $=$ article\&id $=13165$ \&Itemid $=913>$ 
e uma burocracia encarregada da formulação da política). A disseminação de um mercado para Libras e para o Surdo, por outro lado, instaura contradições e disputas materiais em que múltiplos interesses e ideologias se contrapõem em busca de uma resposta para a pergunta da educação bilíngue para surdos.

Contraditoriamente, em que pese o ajuste estrutural das relações de trabalho para atender às demandas do mercado da Libras, a mudança do status quo dos estudantes surdos na conjuntura social continua inalterada, posto que a base material dessa institucionalidade é inconsistente e precária. Na medida em que não há garantias do fomento à existência de comunidades linguísticas em Libras, a subjetividade surda que estaria fundada nessa experiência resume-se a um discurso.

Há uma clara contradição entre o que diz a letra da Lei - a educação bilíngue - e a prática cotidiana das escolas - a educação especial. $\mathrm{Na}$ atual configuração da educação inclusiva e do atendimento educacional especializado (AEE) a Libras não assume centralidade como língua principal na dialogia que envolve estudantes surdos nas escolas. Crianças surdas demandam essas experiências para se tornarem membros efetivos das comunidades linguísticas que lhes dariam o direito à Libras como língua materna. A inexistência de espaços comunitários para sua circulação e complexificação nega à Libras seu caráter ontológico de língua com potencial para se tornar patrimônio cultural da sociedade brasileira.

A Libras como tecnologia assistiva transforma-se em mais uma "mercadoria" a ser consumida socialmente, como se tivesse vida própria e autônoma, desvinculada dos sujeitos que lhe dão vida e conferem sentido nas interações verbais. Essa "fetichização" se materializa nas propostas e práticas que operam pela inclusão obrigatória da Libras no currículo escolar, desarticulada de sua encarnação cultural, social e histórica que circula na comunidade surda.

Essa simplificação da atual planificação da educação de surdos opera a partir de uma lógica formalista que pressupõe que ao incluir a Libras na escola, estariam, por decorrência, incluídos os surdos, ainda que, a despeito da presença da "língua", estivessem suas vozes emudecidas, dissolvidas na cultura oral dominante, e eles continuassem a ser narrados como seres deficientes da linguagem (FERNANDES, 2009).

Na dimensão subjetiva, o direito fundamental à Libras como língua materna e patrimônio cultural e linguístico é cerceado quando, nas experiências em escolas regulares monolíngues, crianças surdas se veem limitadas em suas manifestações cotidianas básicas, seja pela proibição do direito ao aprendizado e uso pleno da Libras, seja pela imposição do português como língua de interação e instrução. Em sua dimensão objetiva, o direito à diversidade linguística é cerceado, quando da inviabilidade da complexificação artístico-literária da 
Libras, pelo silenciamento da arte, literatura e pedagogia surda no currículo escolar, impedindo a manifestação da língua como portadora de valor de referência cultural.

A inclusão escolar de crianças e jovens surdos deveria pressupor uma educação transformadora mediada por experiências linguísticas e culturais plenamente acessíveis ao sujeito da aprendizagem, pela organização de espaços de escolarização específicos para surdos, sobretudo na educação infantil e séries iniciais, promotores do pleno desenvolvimento da Libras e da língua portuguesa como patrimônios históricos e culturais brasileiros. As classes e escolas bilíngues para surdos são taticamente necessárias para essa educação verdadeiramente inclusiva, revolucionária, no sentido de superar o mero respeito às diferenças, especulado pela igualdade de tratamento jurídico como bem tutelado pelo Estado, em direção à real emancipação social dos estudantes e trabalhadores surdos brasileiros.

\section{REFERÊNCIAS}

ALVEZ, Carla B.; FERREIRA, J. P.; DAMÁZIO, Mirlene M. A Educação Especial na Perspectiva da Inclusão Escolar. Abordagem Bilíngue na Escolarização de Pessoas com Surdez. Universidade Federal do Ceará. Brasília: MEC/SEESP, 2010.

BOURDIEU, Pierre. O campo político. Revista Brasileira de Ciência Política, Brasília, n. 5, p. 193-216, jan.jul. 2011.

BRASIL. Constituição da República Federativa do Brasil. Brasília: Imprensa Oficial, 1988.

. Decreto n. 6.571, de 17 de setembro de 2008. Dispõe sobre o atendimento educacional especializado, regulamenta o parágrafo único do art. 60 da Lei no 9.394, de 20 de dezembro de 1996, e acrescenta dispositivo ao Decreto no 6.253, de 13 de novembro de 2007. Diário Oficial da União, Brasília: MEC/SEESP, 18 set. 2008.

. Decreto n. 5.626, de 22 de dezembro de 2005. Regulamenta a Lei no 10.436 , de 24 de abril de 2002, que dispõe sobre a Língua Brasileira de Sinais - Libras, e o art. 18 da Lei no 10.098, de 19 de dezembro de 2000. Diário Oficial da União, Brasília, DF, 23 dez. 2005.

. Relatório do Grupo de Trabalho designado por Portaria Ministerial para elencar subsídios à Política Linguística de Educação Bilíngue - Lingua Brasileira de Sinais e Lingua Portuguesa. Brasília: MEC/SEESP, 2014. 
CALVET, Jean-Louis. Sociolinguística: uma introdução crítica. São Paulo: Parábola, 2002.

FENEIS. Federação Nacional de Educação e Integração dos Surdos. A educação que nós surdos queremos. Documento elaborado pela comunidade surda a partir do pré-congresso ao V Congresso latino-americano de Educação Bilíngue para Surdos, realizado em Porto Alegre/RS, no salão de atos da reitoria da UFRGS, nos dias 20 a 24 de abril de 1999. Disponível em: <http://www.feneis.org.br/arquivos/A\%20EDUCA\% C7\%C3O\%20 QUE\%20N\%D3S\%20SURDOS\%20QUEREMOS.doc>. Acesso em: 10/12/2013.

FERNANDES, S. Avaliação escolar e educação bilíngue para surdos: a questão das línguas na política de inclusão. São Carlos-SP: UFSCAR. In: ALMEIDA, Maria Amelia; MENDES, E. G.; HAYASHI, Maria Cristina I. (Org.). Temas em Educação Especial. Araraquara: Junqueira\&Marin Editores, no prelo.

. Língua de sinais e escolarização de surdos. O que pode e o que quer essa língua? Revista Direcional Educador, São Paulo, maio 2009.

. Avanços e perspectivas de inclusão escolar para surdos. In: X CONGRESSO INTERNACIONAL XVI SEMINÁRIO NACIONAL DO INES Educação de Surdos: a conquista de novos territórios, 2011, Rio de Janeiro. Anais do Congresso: educação de surdos: a conquista de novos territórios [X Congresso Internacional do INES e XVI Seminário Nacional do INES]. Rio de Janeiro: Instituto Nacional de Educação dos surdos, 2011. p. 106-110.

FERNANDES, Sueli; MOREIRA, L. C. Desdobramentos político-pedagógicos do bilinguismo para surdos: reflexões e encaminhamentos. Revista Educação Especial (UFSM), v. 22, p. 225-236, 2009.

GRUPIONI, L. D. B. Do nacional ao local, do Federal ao Estadual: as leis e a educação escolar indígena. In: MARFAN, Marilda Almeida (Org.). Congresso Brasileiro de Qualidade na Educação: formação de professores: educação escolar indígena. Brasília: MEC/SEF, 2001, p. 130-136. Disponível em: <http://portal.mec.gov.br/seb/arquivos/ pdf/vol4c.pdf>. Acesso em: 05/02/2014.

HALL, Stuart. A identidade cultural na pós-modernidade. 4. ed. Rio de Janeiro: DP\&A, 1997.

IANNI, O. A racialização do mundo. Tempo Social, Revista de Sociologia da USP, v. 8, n. 1, p. 1-25, maio 1996 .

LABORITT, Emmanuelle. O vôo da gaivota. São Paulo. Best Seller, 1994.

LANE, Harlan. When the mind hears: a history of the deaf. New York: Random House, 1984.

LOPES, Maura C. Surdez \& Educação. Belo Horizonte: Autêntica, 2007.

MCLAREN, Peter. Multiculturalismo crítico. São Paulo: Cortez, 1997. 
MARTINS, C. F. M. Algumas especulações lingüísticas na tradição italiana: Pietro Bembo e a "Questione della lingua". 2011. (Apresentação de Trabalho/Comunicação). Disponível em: < http://www.letras.ufrj.br/neolatinas/media/publicacoes/cadernos/a5n5/ estlin/claudiafatima_martins.pdf $>$. Acesso em: 13/03/2014.

SAWAIA, B. (Org.) As artimanhas da exclusão: análise psicossocial e ética da desigualdade social. 2. ed. Petrópolis: Vozes, 2001.

SKLIAR, C. (Org.). A surdez: um olhar sobre as diferenças. Porto Alegre: Mediação, 1998.

STROBEL, Karin L. Surdos: vestígios culturais não registrados na história. Tese (Doutorado) - Universidade Federal de Santa Catarina. Florianópolis, 2008. Disponível em: $<$ http://www.ronice.cce.prof.ufsc.br/index_arquivos/Documentos/karinstrobel.pdf $>$. Acesso em: 12/02/2014.

THOMA, Adriana da Silva; KLEIN, Madalena. Experiências educacionais, movimentos e lutas surdas como condições de possibilidade para uma educação de surdos no Brasil. Cadernos de Educação. FaE/PPGE/UFPel: Pelotas, maio/agosto 2010. p. 107-131.

Texto recebido em $1^{\mathrm{o}}$ de julho de 2014 . Texto aprovado em 08 de agosto de 2014. 
